\title{
Estudo de Viabilidade da Reutilização de Banners de Lona na Produção de Móveis
}

\author{
Feasibility Study of Reusing Tarp Banners \\ in the Furniture Production
}

Danieli Maehler Najeliski ${ }^{a}$

Ana Paula Palhanob

Lucas Gabriel Matosoc

${ }^{a}$ Doutoranda em Design pela Universidade Federal do Rio Grande do Sul, Porto Alegre, RS, Brasil End. Eletrônico: danielinejeliski@gmail.com

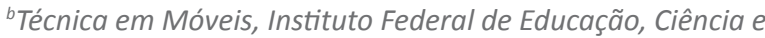
Tecnologia Farroupilha, Santa Rosa, RS, Brasil End. Eletrônico: aninhappalhano@gmail.com

'Técnico em Móveis, Instituto Federal de Educação, Ciência e Tecnologia Farroupilha, Santa Rosa, RS, Brasil End. Eletrônico: lucas.gabriel.matoso@gmail.com

doi:10.18472/SustDeb.v8n2.2017.24730

\section{RESUMO}

A lona vinílica é um material de custo acessível com boa qualidade de impressão, por isso é muito utilizada para a confecção de banners para campanhas publicitárias e eventos acadêmicos. Em ambas, as aplicações se transformam rapidamente em resíduos. Nesse contexto, foi idealizado um projeto de pesquisa com o objetivo de estudar a viabilidade da reutilização dos banners de lona na produção de móveis. O projeto foi desenvolvido com os alunos do Curso Técnico em Móveis do Instituto Federal Farroupilha (IFFar), Campus Santa Rosa. Na primeira etapa foram realizados testes de corte, união, acabamento e deformação. Constatou-se que o corte da lona é viável. A união com adesivos foi insatisfatória e o método com melhores resultados foi a união mecânica com grampos metálicos. Com relação ao acabamento, as tintas não cobriram a superfície de maneira homogênea. Quanto à resistência, a lona vinílica sofreu deformação plástica com a aplicação de carga localizada. Com restrições, a aplicação do material na produção de móveis foi considerada viável. Na segunda etapa foram desenvolvidos o projeto e o protótipo de luminárias de coluna, uma mesa de centro, bancos dobráveis e nichos empilháveis. $\mathrm{O}$ projeto dos produtos priorizou a reutilização e o uso racional das matérias-primas, o processo produtivo simplificado e a estética contemporânea, condizentes com os preceitos do Ecodesign e do princípio da viabilidade econômica.

Palavras-chave: Ecodesign; Reutilização; Banners de Lona; Mobiliário. 


\begin{abstract}
Vinyl tarp is a low-budget material with good print quality, being widely used for making banners for advertising campaigns and academic events. In both applications, it quickly turns into waste. In this context, a research project was designed with the objective of studying the feasibility of reusing tarp banners in the furniture production. The project was developed with students of the Technical Course in Furniture of the Federal Institute Farroupilha (IFFar), Santa Rosa Campus. In the first stage, tests on cutting, joining, finishing and deforming were performed. The cutting of the material was considered feasible. The bonding with adhesives was unsatisfactory, with best results with mechanical bonding with metallic clips. Regarding the finish, paints were not able to cover homogeneously the surface. As for the resistance, the vinyl tarp underwent plastic deformation with the application of localized load. With restrictions, use of the material for production of furniture was considered viable. In the second stage, the design and prototype of column luminaires, coffee tables, folding benches and stackable niches were developed. The design of products prioritized the reuse and rational use of raw materials, a simplified production process and a contemporary aesthetic, consistent with the precepts of Ecodesign and economic viability.
\end{abstract}

Keywords: Ecodesign; Reuse; Vynil Banners; Furniture.

\title{
1 INTRODUÇÃO
}

Toda atividade humana gera algum resíduo ou impacto no meio ambiente. As atividades industriais, por sua natureza, intensificam esse processo, de modo que a destinação dos rejeitos é um problema contínuo e de ordem cumulativa. As matérias-primas são extraídas da natureza, processadas e transformadas em produtos industriais para abastecer o mercado, produzindo resíduos que são devolvidos para a biosfera. Para Kazazian (2005, p. 51), esse ciclo "resulta em um duplo desequilíbrio: de um lado, o esgotamento dos recursos naturais, de outro, um aumento crescente dos resíduos provenientes do consumo, que são fontes de poluição".

O processo e o período de degradação são específicos para cada material e variam de acordo com a composição química deste. De um modo geral, os materiais orgânicos, como a madeira e o bambu, degradam em um intervalo de tempo consideravelmente menor que os materiais sintéticos. A degradação dos materiais orgânicos é favorecida pela ação das condições ambientais e dos fungos, que atuam na deterioração dos componentes dos materiais. Já os materiais sintéticos, especialmente os derivados do petróleo, possuem um ciclo de decomposição muito longo, podendo demorar centenas de anos (ASHBY; JOHNSON, 2011). A demora no processo se deve à natureza química desses materiais, que dificulta ou mesmo inviabiliza a deterioração por meios naturais.

Não obstante, os polímeros sintéticos são os materiais mais utilizados pela indústria, nas mais diferentes aplicações em função da versatilidade e do custo acessível. Na indústria gráfica também os polímeros são representativos, estão presentes na composição da maioria das tintas, na produção de embalagens e suportes para material impresso de todos os tipos. Os banners de lona são um exemplo de material polimérico muito utilizado em campanhas publicitárias e eventos acadêmicos.

Os banners são confeccionados geralmente em lona vinílica, cujo principal componente é o Policloreto de Vinila (PVC), composto químico derivado do petróleo, recurso não renovável. Apresentam elevado tempo de decomposição, e possuem o agravante da dificuldade da reciclagem do material, por isso são enviados aos aterros sanitários sem nenhuma separação ou aproveitamento (JUNG et al., 2015). A própria finalidade da utilização, em campanhas publicitárias e eventos acadêmicos, faz com que o material se torne obsoleto rapidamente, pois as informações divulgadas têm prazo de validade, geralmente a duração da campanha ou do evento.

A maioria dos eventos científicos organizados por instituições de ensino mantém como uma das categorias de apresentação de trabalhos os banners. Para ilustrar, apenas na VI Mostra da Educação Profissional e Tecnológica (MEPT) realizada pelo Instituto Federal Farroupilha, Campus São Borja, no ano de 2015, foram apresentados 252 trabalhos acadêmicos na modalidade pôster. Assim, a geração de resíduos desse material é constante e torna-se um problema de descarte para as instituições. 
O Ecodesign é uma abordagem que tem como objetivo reduzir os impactos negativos de um produto ao meio ambiente, conservando a qualidade de uso, a funcionalidade e o desempenho, com vistas a melhorar a qualidade de vida dos usuários (KAZAZIAN, 2005). Assim, os aspectos ambientais são tratados com o mesmo status que a funcionalidade, durabilidade, custos, estética, ergonomia e qualidade (PIGOSSO et al., 2010). Para Platcheck et al. (2007), é importante que os aspectos do Ecodesign sejam considerados desde a fase de concepção do projeto, considerando o ciclo de vida completo do produto, desde a aquisição de matérias-primas até a deposição final destas.

Existem várias ferramentas que auxiliam e orientam a prática do Ecodesign. De acordo com Sheldrick e Rahimifard (2013), os primeiros métodos direcionados às demandas ambientais começaram a surgir durante os anos de 1980 e 1990, com a denominação genérica de Design for X (DfX), onde o X é uma variável que permite a incorporação sistemática de preocupações ambientais vigentes. As principais variáveis são: DfA - Design for Assembly (Design para a montagem), DfM - Design for Manufacture (Design para a manufatura), DfS - Design for Service (Design para o serviço) e o DfD - Design for Disassembly (Design para a desmontagem, também conhecida como Design para a reciclagem). Esse conjunto de ferramentas foi evoluindo e ainda é muito utilizado.

O DfD - Design for Disassembly é orientado a partir dos 3Rs: reduzir, reutilizar e reciclar, nessa ordem. Segundo Kindlein Júnior et al. (2002), o primeiro R, de reduzir, está relacionado ao consumo e produção conscientes, à redução do desperdício. Já o segundo $R$, de reutilizar, significa utilizar novamente os sistemas e subsistemas dos objetos em sua forma original, onde inclui-se também a reutilização dos materiais descartados para a fabricação de outros produtos. Por fim, o terceiro R, de reciclar, consiste em aproveitar dos produtos descartados os materiais que podem voltar para as indústrias de reciclagem, como matéria-prima para a fabricação de novos produtos.

O segundo $\mathrm{R}$, a reutilização, é a segunda vida de um produto ou resíduo, muitas vezes Ihe dando outro uso, papel, significado e até aparência. É definida por Fuad-Luke (2004) como o uso do material sem que seu estado original seja alterado. Reutilizar é uma forma de evitar que seja descartado aquilo que ainda pode ser utilizado. Para Gomes (2011), na hierarquia dos resíduos, a reutilização está acima da reciclagem em termos de valorização do material. Na primeira há um maior aproveitamento do valor material e energético dos resíduos, já que envolve um menor esforço adicional para voltar a reintegrálos em novos produtos. Segundo Padilha (2000), o consumo de energia na produção de materiais é da ordem de $15 \%$ a $25 \%$ de toda a energia primária utilizada nas economias industrializadas, daí a importância de racionalizar esse processo.

O acúmulo de resíduos de banners de lona vinílica é um problema comum às instituições de ensino. Por isso, iniciativas para a reutilização desse material vêm se disseminando. A maioria dos trabalhos encontrados na literatura descrevem projetos de pesquisa e extensão que têm como objetivo a confecção de produtos para complemento de renda de comunidades vulneráveis. Esses projetos partem de diferentes esferas das universidades, não necessariamente vinculados à área de Design. Em geral, propõem a reutilização dos banners de lona na produção de acessórios escolares como mochilas, bolsas e estojos. Como exemplo, pode-se citar os projetos: Kid Vinil da Unesp (GOYA; MARTINUSSI; ROSA, 2010), o Re-utilize da Furg (D’AVILA; LENZI, 2014), o Relona da UFSM (JUNG et al., 2015) e o Ecobanner da Univille (HERMES; MORGENSTERN, 2016). Nesses projetos o foco não é o design de novos produtos, tanto que não são utilizadas metodologias específicas da área. A definição dos produtos a serem produzidos tem como requisitos a facilidade de produção e de comercialização na comunidade escolar.

Com o objetivo de pesquisar a viabilidade da reutilização dos banners de lona em desuso no IFFar, Campus Santa Rosa, no projeto de produtos com maior valor agregado, contemplando as premissas do Ecodesign, foi idealizado o projeto de pesquisa "Reutilização de banners de lona na produção de mobiliário". A iniciativa foi direcionada aos alunos do terceiro ano do Curso Técnico em Móveis Integrado da instituição. Os estudos de viabilidade foram realizados em turnos opostos às aulas, enquanto que o projeto e a produção dos protótipos foram desenvolvidos no Laboratório de Móveis, ao longo da disciplina de Processo de Fabricação III. 
O projeto foi desenvolvido em duas etapas. Em um primeiro momento foram realizados testes para verificar a viabilidade da aplicação da lona vinílica oriunda dos banners na produção de mobiliário. Na sequência, foram selecionadas as técnicas consideradas mais exitosas e, a partir destas teve início o processo de projeto. A partir de uma metodologia de projeto de produto específica, foi realizada pesquisa de informações e de produtos similares, geração de alternativas e escolha das propostas mais adequadas, o posterior detalhamento dos produtos e, por fim, a produção dos protótipos.

\section{MATERIAIS E MÉTODOS}

Para a realização do estudo foram utilizados banners de lona coletados nas dependências do IFFar Campus Santa Rosa, junto aos servidores, a partir do pré-requisito de serem considerados resíduos. O material arrecadado é composto por pôsteres de congressos científicos e material institucional. A definição dos testes de viabilidade a serem realizados foi baseada nos materiais e técnicas de produção de móveis que são utilizados nas aulas práticas no Laboratório de Móveis da instituição.

No Brasil, a madeira é a principal matéria-prima na indústria moveleira, seja maciça, ou na forma de materiais derivados, como o MDF (Medium Density Fiberboard), compensados e aglomerados. No caso das pequenas e médias empresas, a maioria utiliza a madeira maciça como matéria-prima para a fabricação de seus produtos. Já nas grandes empresas, o MDF se destaca (CASSILHA et al., 2003). Nesse contexto, optou-se por utilizar a madeira e o MDF como materiais estruturais nos testes de viabilidade.

$\mathrm{Na}$ etapa de preparo da matéria-prima, foram realizados testes de corte da lona vinílica, utilizando tesoura e estilete. Na sequência, foram realizados testes de união da lona com os materiais estruturais a partir de adesivo e de união mecânica. No processo de acabamento, foram aplicados três tipos diferentes de tintas utilizadas na indústria moveleira. Por fim, a partir de uma estrutura simples, foi realizado um ensaio de deformação do material. A Tabela 1 descreve detalhadamente o tipo do ensaio realizado, o método e o respectivo material.

Tabela 1 - Descrição dos ensaios de viabilidade realizados com a lona proveniente de banners

\begin{tabular}{|l|l|l|}
\hline Ensaio & Método & Material \\
\hline \multirow{3}{*}{ Corte } & Manual & $\begin{array}{l}\text { Tesoura } \\
\text { Estilete }\end{array}$ \\
\hline \multirow{3}{*}{ União } & \multirow{2}{*}{ Adesivo } & $\begin{array}{l}\text { Cola branca } \\
\text { Cola para madeira } \\
\text { Cola de contato }\end{array}$ \\
\cline { 2 - 3 } & Mecânica & Grampos \\
\hline \multirow{2}{*}{ Deformação } & Pincel & $\begin{array}{l}\text { Tinta nitrocelulose } \\
\text { Tinta à base de água }\end{array}$ \\
\cline { 2 - 3 } & Spray & Spray \\
\hline
\end{tabular}

Fonte: os autores. 
Os banners de lona vinílica possuem largura que varia de $80 \mathrm{~cm}$ a $100 \mathrm{~cm}$ e comprimento variável que depende da aplicação. Uma medida considerada padrão para os pôsteres de eventos científicos é $80 \mathrm{~cm}$ $x 120 \mathrm{~cm}$. Assim, o primeiro processo para a reutilização do material é o corte. Foram realizados testes de corte com tesoura e com estilete.

A lona vinílica possui duas superfícies com características bem distintas. O lado que recebe a impressão é liso (Figura 1a), enquanto que o verso do material possui uma textura (Figura 1b), oriunda da trama do processo de produção do material, e cor que varia do preto ao cinza. Os testes de união contemplaram a aderência entre amostras de lona vinílica e entre amostras de lona com a madeira e o MDF.

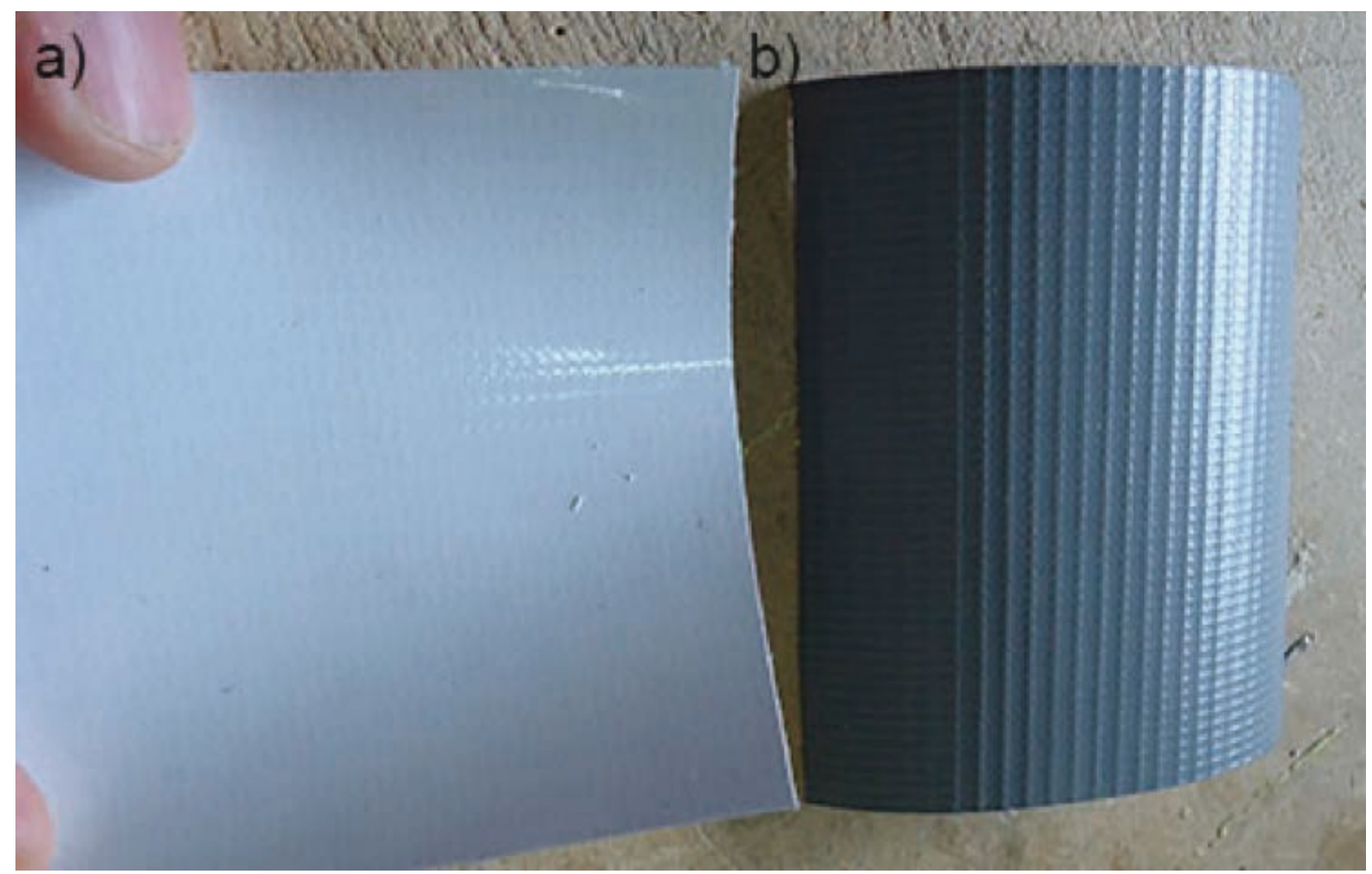

Figura 1 - Características da superfície da lona vinílica: a) face frontal, lisa, que recebe a impressão; b) face posterior, com textura.

Fonte: os autores.

Foram utilizados três tipos de adesivos: cola branca, cola de contato e cola de madeira. Os adesivos diferem entre si tanto na composição quanto na forma de aplicação e cura. A cola branca e a cola para madeira são aplicadas com pincel sobre a superfície lisa e limpa, são à base de água e após a aplicação a união das peças deve ser realizada instantaneamente e aguardar o tempo de cura, que demora cerca de 24 horas. Já a cola de contato deve ser aplicada com pincel em ambas as peças a serem unidas, após a aplicação deve-se esperar a cura do adesivo, que demora alguns minutos, para então efetuar a união das peças e a secagem final. A limpeza dos pincéis, após a aplicação da cola de contato, deve ser realizada com thinner (solvente). Para os testes de união com adesivos foram confeccionadas amostras de lona, de madeira e de MDF com dimensões de $7 \mathrm{~cm} \times 7 \mathrm{~cm}$ (Figura 2). 


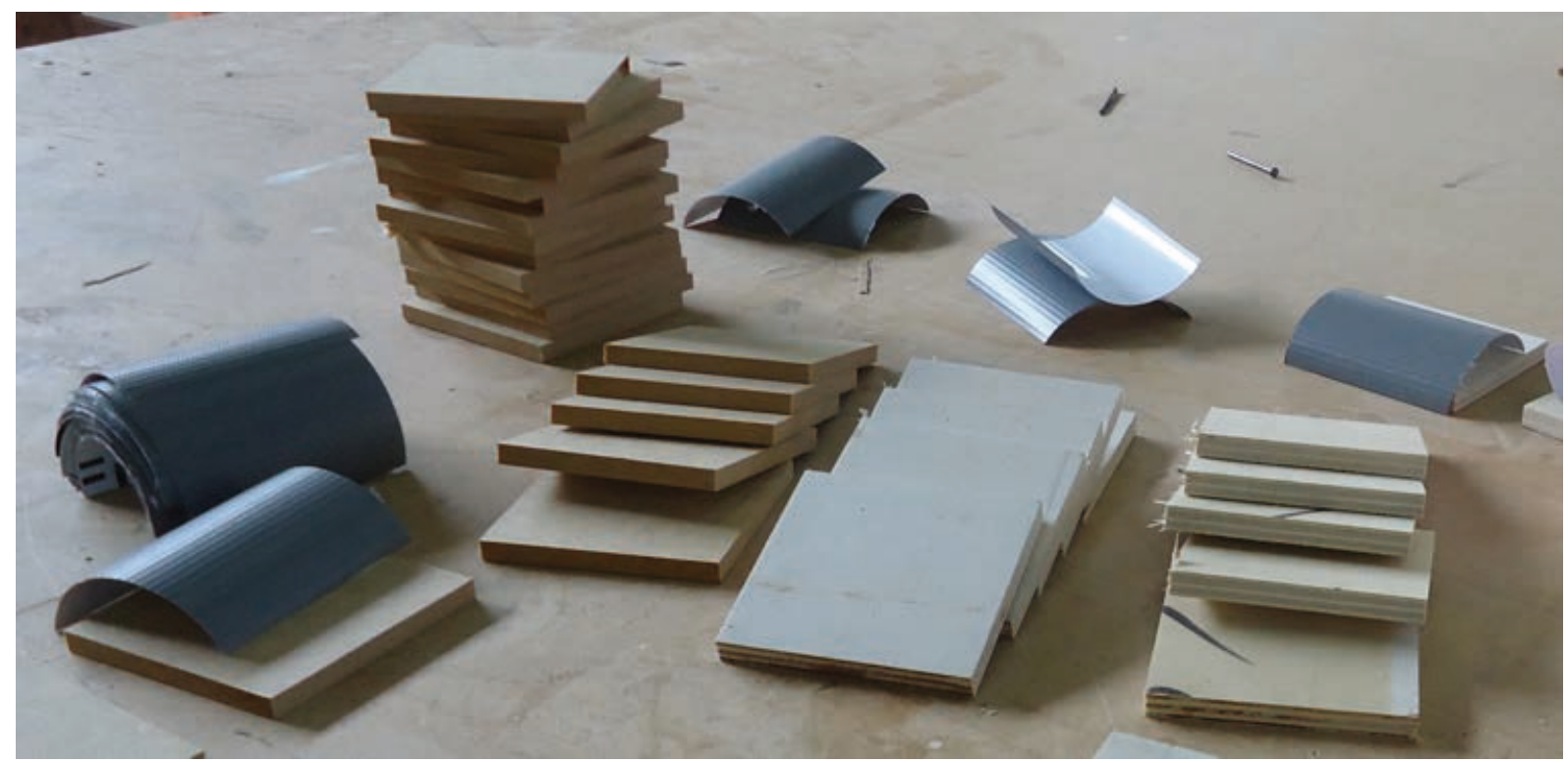

Figura 2 - Amostras de lona vinílica, de madeira e de MDF prontas para a aplicação dos adesivos para os testes de união

Fonte: os autores.

Para os ensaios de união entre amostras de lona, foram testadas três diferentes configurações de aderência, a saber: face lisa com face lisa, face lisa com face com textura e as duas faces com textura. Para cada configuração foram aplicados os três tipos de adesivo separadamente, sendo três amostras para cada, totalizando 27 amostras. Os testes de união com adesivos entre lona e madeira e lona e MDF, seguiram os mesmos princípios. Foram testadas quatro configurações diferentes, a saber: face lisa da lona com madeira, face lisa com MDF, face com textura com madeira e face com textura com MDF. Da mesma forma, para cada configuração foram aplicados os três tipos de adesivo separadamente, sendo três amostras para cada, totalizando 36 amostras. A Figura 3 ilustra algumas etapas do processo descrito acima.
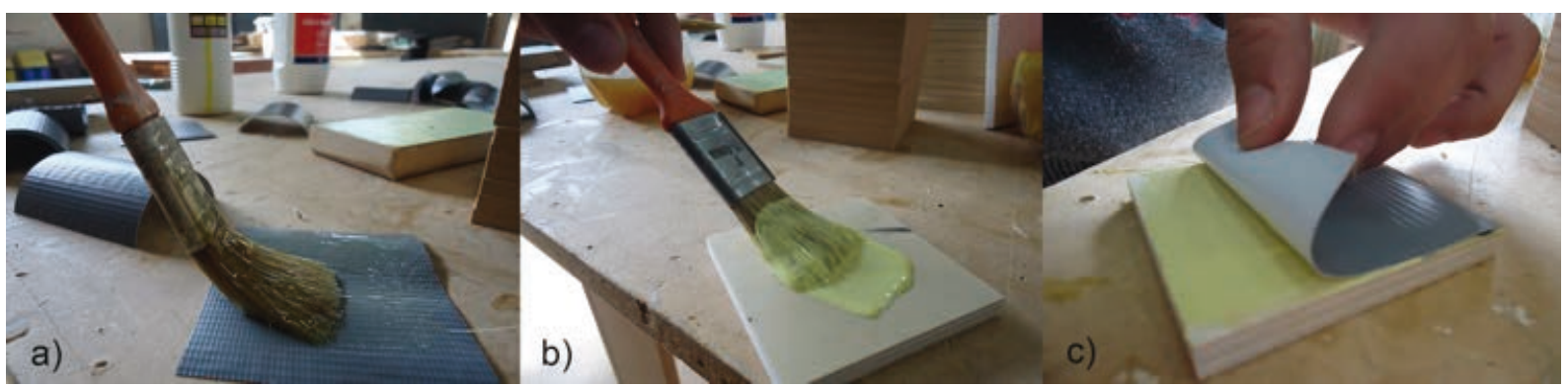

Figura 3 - Testes de união com adesivos: a) aplicação da cola de contato na face com textura da lona; b) aplicação da cola de madeira na superfície do MDF; c) união entre a face lisa da lona e a superfície da madeira, com cola para madeira

Fonte: os autores.

Para os testes de união mecânica, foram confeccionadas três molduras de madeira com dimensões de $40 \mathrm{~cm} \times 40 \mathrm{~cm}$, com $5 \mathrm{~cm}$ de largura e $2 \mathrm{~cm}$ de espessura. Foram cortadas amostras de lona com dimensões de $45 \mathrm{~cm} \times 45 \mathrm{~cm}$, com folga para a aplicação dos grampos na parte posterior da moldura (Figura 4). Para a fixação, foram utilizados os grampos metálicos, aplicados com o auxílio de uma pistola com pressão. 


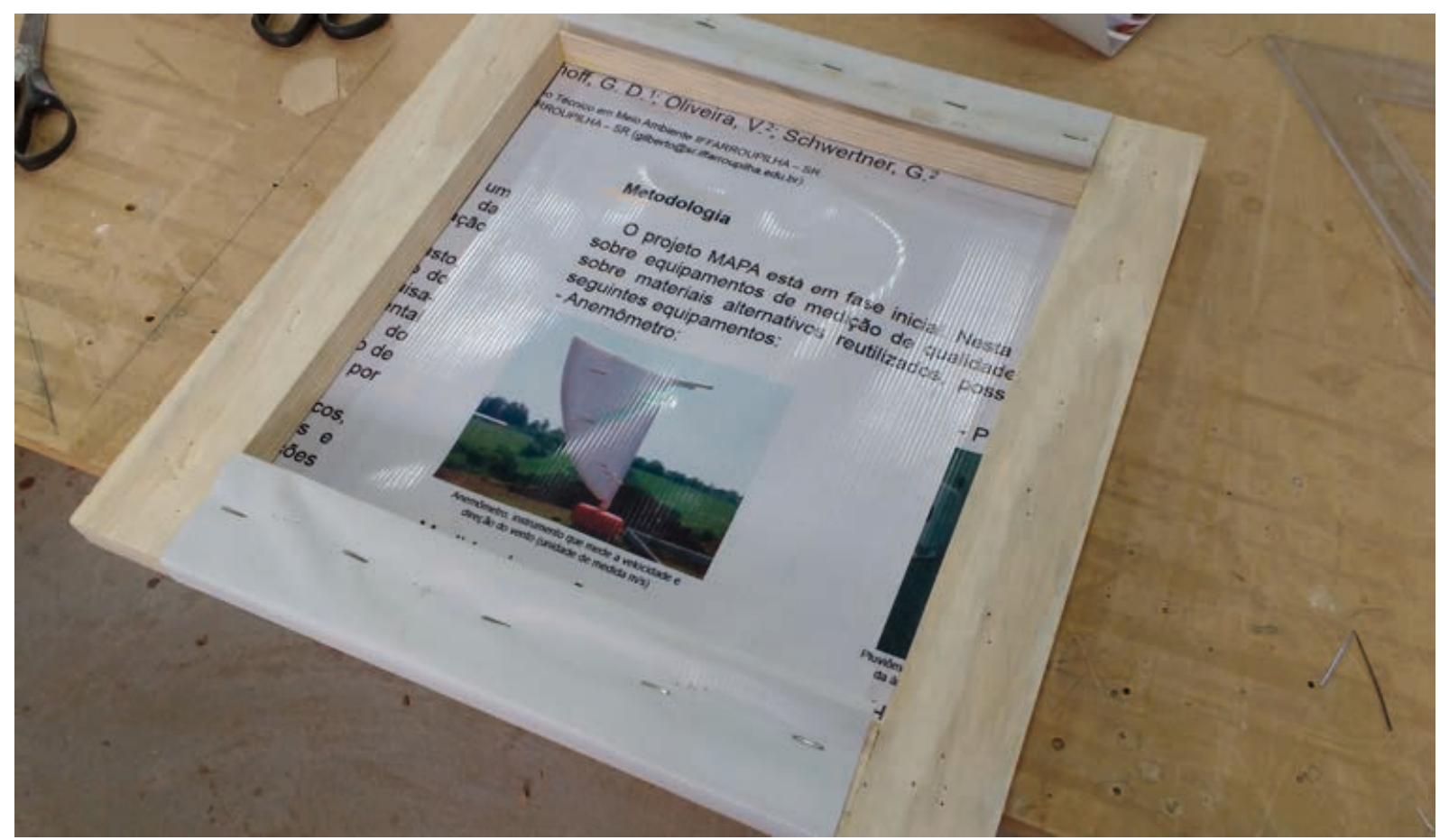

Figura 4 - Parte posterior da moldura de madeira com a união da lona por meio de grampos metálicos.

Fonte: os autores.

Referente ao processo de acabamento, foram realizados testes de pintura na superfície texturizada da lona, que não recebe impressão. Foram utilizadas tintas à base de água e nitrocelulose, ambas aplicadas com pincel e tinta spray. Cada tipo de tinta foi aplicado em três amostras de lona, com uma e duas demãos, respectivamente.

Por fim, foi realizado um teste básico de deformação da lona vinílica. Para tanto, foram utilizadas as molduras confeccionadas para testar a união mecânica por meio de grampos metálicos (Figura 4). 0 objetivo do ensaio foi de visualizar o comportamento do material quando submetido à pressão de uma carga localizada. Para a aplicação da carga, foram utilizados dez blocos de concreto de $10 \mathrm{~kg}$ cada. A moldura foi acomodada sobre uma base de blocos de modo que a parte central da lona ficasse livre, sem nenhum apoio inferior. Na sequência, os blocos de concreto foram empilhados um a um, com um pequeno intervalo entre cada um, totalizando $100 \mathrm{~kg}$.

Na segunda etapa, as atividades de projeto dos móveis foram realizadas ao longo da disciplina de Processo de Fabricação III, do Curso Técnico em Móveis Integrado, no ano de 2016. A turma foi dividida em quatro grupos, sendo que cada grupo projetou um produto. Para o desenvolvimento do projeto dos produtos, foi utilizada a metodologia de projeto da área de design proposta por Löbach (2001), que é dividida em quatro etapas distintas: análise do problema, geração de alternativas, avaliação das alternativas e realização da solução do problema.

Inicialmente foi definido o problema: como reutilizar banners de lona na produção de móveis? Com o problema definido, partiu-se para a coleta de informações por meio de pesquisa de referências na internet. Nessa fase, foram coletadas informações de produtos existentes que reutilizam a matériaprima, ideias de móveis que podem ser produzidos e especificações de produção. Após a análise das informações foram definidos os requisitos de projeto para todos: a viabilidade e facilidade de produção e a utilização da lona como elemento funcional no móvel, não apenas estético.

Na sequência, cada grupo definiu o seu produto e teve início a etapa de geração de alternativas, por meio do esboço de ideias à mão livre. Posteriormente, foi realizada a avaliação das alternativas geradas e a seleção da proposta mais condizente com os requisitos de projeto previamente definidos. Por 
fim, foi realizada a etapa de solução do problema, mediante o detalhamento técnico do produto e a produção de protótipos.

\section{RESULTADOS}

Ao término dos testes de viabilidade, foi realizada a avaliação dos resultados e a definição das melhores práticas. Com relação ao corte, ambos os métodos, com tesoura e com estilete, mostraram-se eficientes. A trama da textura na superfície posterior da lona facilita para deixar o corte no esquadro. A espessura fina do material favorece o corte e o bom acabamento.

Com relação aos testes de união, os adesivos e a união mecânica obtiveram resultados muito distintos. De um modo geral, a união por meio de adesivos entre amostras de lona foi ineficiente (Figura 5b e Figura 5c). Nenhuma das amostras obteve aderência entre as duas partes por meio do adesivo. 0 fato de a lona vinílica e as colas serem constituídas essencialmente de material polimérico dificulta a aderência. Os polímeros formam em sua superfície uma fina camada repelente, de modo que, após a cura, o adesivo se torna uma camada à parte.

Já para a união entre as peças de madeira e MDF com as amostras de lona, as colas branca e para madeira foram ineficientes. Após a cura, o adesivo forma uma camada independente dos demais materiais, similar ao resultado da união entre amostras de lona. A cola de contato foi a que obteve o resultado mais satisfatório na união da lona com os materiais estruturais. Houve aderência entre os materiais (Figura 5a), embora o processo de cura foi prejudicado pela umidade.

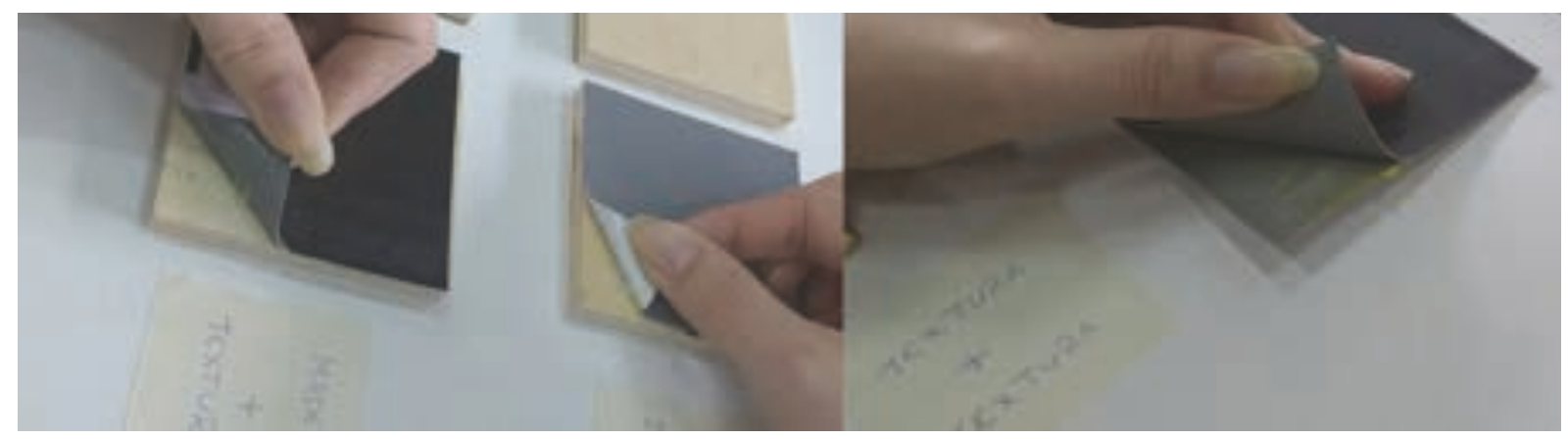

Figura 5 - Resultados da aplicação dos adesivos: a) cola de contato aplicada na parte posterior da lona e na madeira; b) cola branca aplicada nas faces posteriores da lona; c) cola para madeira aplicada nas faces da lona com impressão.

Fonte: os autores.

Dos testes de união realizados, a união mecânica da lona com os materiais estruturais foi a que obteve os resultados mais satisfatórios. A união de materiais distintos por meio de grampos metálicos aplicados por pressão é corriqueira na produção de estofados. O processo é simples, rápido e altamente eficiente. Todo o peso da carga recaiu sobre os grampos, que sustentam a lona, ainda assim estes continuam intactos, comprovando a eficiência do método.

O ponto negativo da união por meio de grampos metálicos é o acabamento, de modo que a aplicação deve ser realizada nas superfícies inferiores ou internas do móvel que não ficam visíveis. Assim, dos testes de união realizados, a união mecânica por meio de grampos metálicos aplicados com pressão é a mais eficiente para produtos sujeitos à ação de cargas e deformação, como, por exemplo assentos de bancos e cadeiras. Já a união com cola de contato entre a lona e os materiais estruturais é recomendável apenas em situações onde esta não vai sofrer aplicação de carga ou força excessivas, como em acessórios e peças decorativas. 
Com relação ao acabamento, os testes de pintura da lona vinílica obtiveram resultados insatisfatórios. A Figura 6 mostra o acabamento das amostras após a secagem das tintas: nitrocelulose (Figura 6a), à base de água (Figura 6b) e spray (Figura 6c), sendo as três amostras superiores de cada com uma demão e as três inferiores com duas demãos. A tinta nitrocelulose obteve uma cobertura da superfície razoável após a segunda demão (Figura 6a). Já a tinta à base de água foi a que resultou no pior desempenho, já que a superfície da lona repeliu a tinta (Figura 6b). De todas, a tinta spray foi a que obteve os melhores resultados de cobertura (Figura $6 c$ ), entretanto, foi a que mais deformou a superfície da lona.

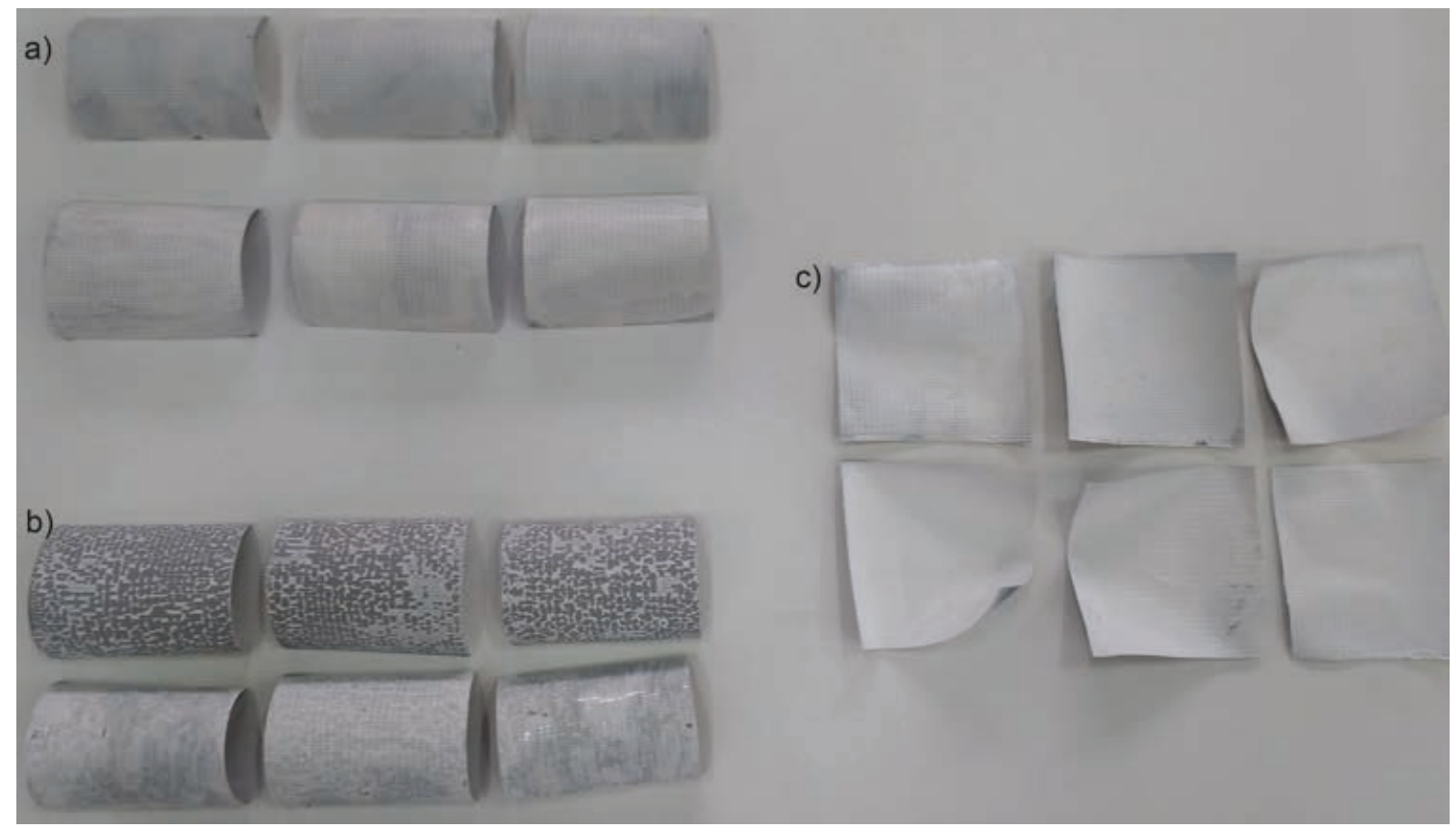

Figura 6 - Resultado dos testes de pintura: a) tinta nitrocelulose, parte superior com uma demão e parte inferior com duas; b) tinta à base de água, uma e duas demãos; c) tinta spray, uma e duas demãos.

Fonte: os autores.

Assim, com relação ao acabamento, a alternativa mais viável é a reutilização da lona vinílica em seu acabamento original. A superfície que recebe a impressão, que é lisa, vai variar em cores e grafismos conforme o conteúdo apresentado. Já a superfície posterior possui a textura da trama do material e cores que variam do cinza ao preto (Figura 7). O acabamento da lona, tanto da superfície impressa quanto da posterior, pode gerar composições esteticamente agradáveis quando combinado com a madeira natural. Ainda, a reutilização do material em seu acabamento original elimina uma etapa da produção, otimizando o processo. 


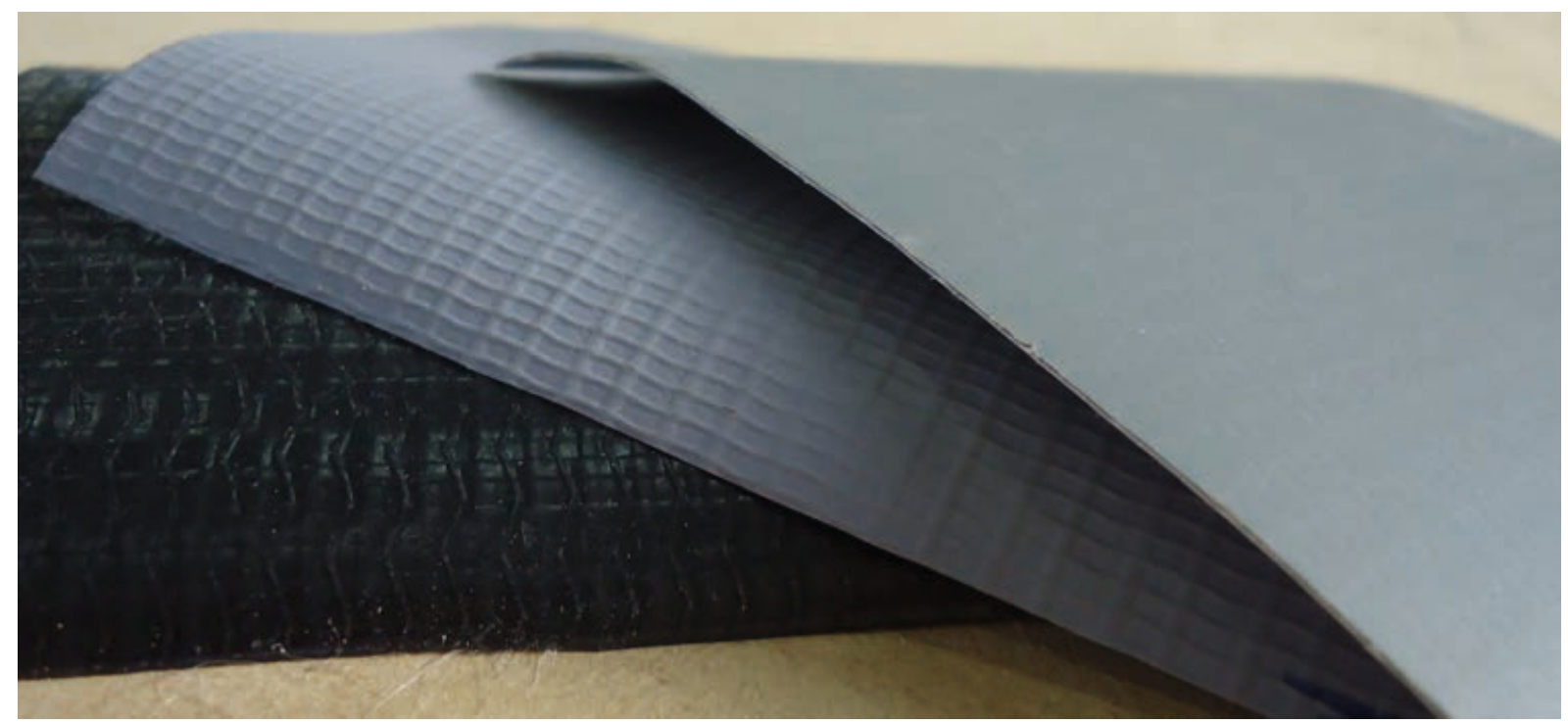

Figura 7 - Detalhe das cores e da textura da superfície posterior das lonas de banners.

Fonte: os autores.

Por fim, os resultados do teste de resistência do material mostraram que a lona vinílica é propensa a sofrer deformação sob a ação de carga localizada. A fixação realizada por meio de grampos metálicos não cedeu com a aplicação de $100 \mathrm{~kg}$, nem mesmo a lona no entorno da união sofreu qualquer alteração (Figura 8b), também não rompeu com a aplicação da carga. A deformação do material, característica dos materiais poliméricos, pôde ser observada após a retirada da carga e ocorreu em pontos estratégicos. A deformação concentrou-se na região sem o apoio da estrutura de madeira (Figura 8a). Trata-se de uma deformação plástica, ou seja, permanente, onde o material não retorna ao estado original depois de retirada a carga aplicada. Assim, infere-se que a lona oriunda dos banners pode ser utilizada em condições de aplicação de cargas leves.

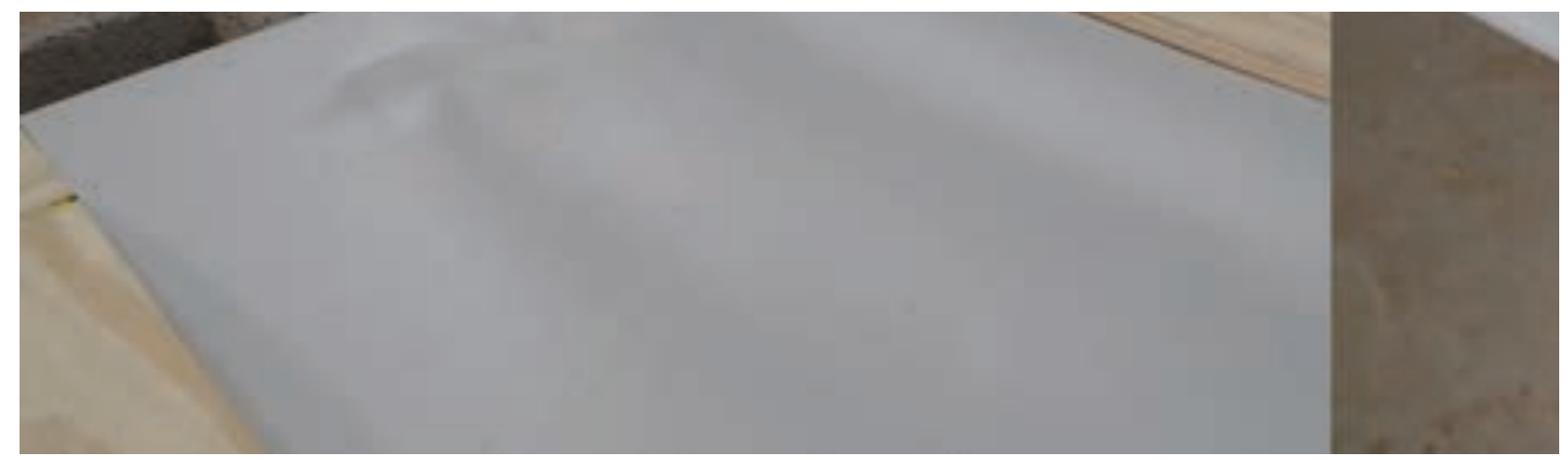

Figura 8 - Resultado dos testes de resistência: a) deformação plástica da lona; b) fixação com grampos intacta.

Fonte: os autores.

Ao término dos testes de viabilidade, concluiu-se que a lona dos banners é passível de ser reutilizada na produção de móveis, com devidas restrições. A união do material com a madeira e o MDF é viável, adquirindo maior resistência com a utilização de grampos metálicos, com a alternativa do emprego da cola de contato em situações sujeitas a menos impacto e que exijam melhor acabamento superficial. A exploração do acabamento original da lona é a alternativa de acabamento mais viável, tendo as opções da frente e do verso do material. 
A aplicação da lona vinílica em situações sujeitas à ação de cargas é possível, desde que essas sejam reduzidas. Ainda, quanto menor a área da amostra, menor será a deformação sofrida, de modo que a aplicação em peças de mobiliário com grandes dimensões não é recomendável. Por se tratar de um polímero, a lona está sujeita à ação do calor, que favorece a deformação. Portanto, não é recomendada a sua aplicação em móveis para áreas sob exposição do sol por períodos prolongados.

Com relação ao projeto, na primeira etapa, de análise do problema, cada grupo desenvolveu um painel semântico com imagens de móveis e acessórios que serviram como referência para a geração de alternativas. Na Figura 9 pode-se observar uma síntese das referências utilizadas.

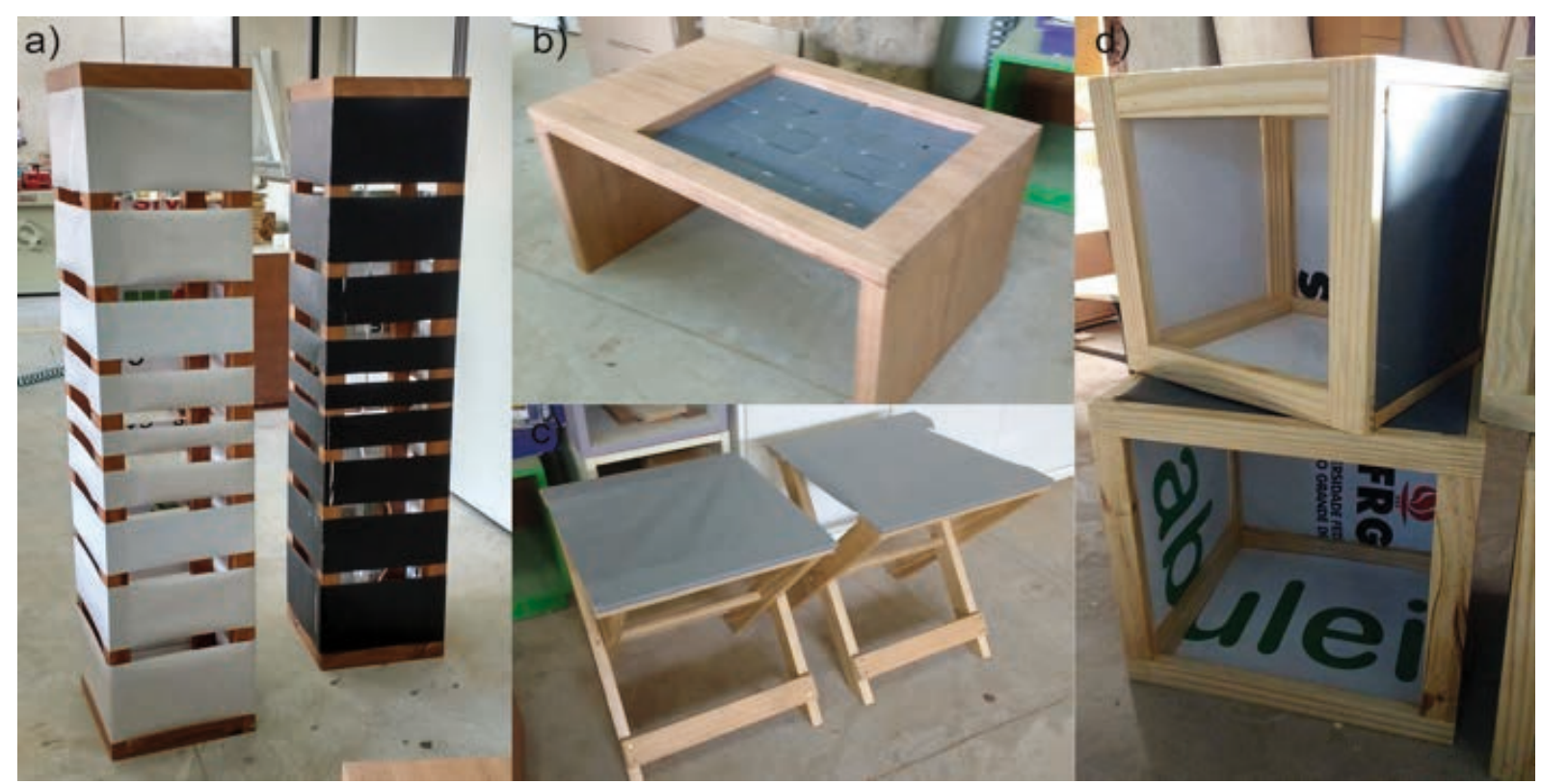

Figura 9 - Síntese das imagens utilizadas como referência para a etapa de geração de alternativas.

Fonte: Pinterest.

Após a pesquisa de informações e referências, teve início a etapa de geração de alternativas (Figura 10). Cada grupo trabalhou em cima da sua proposta de móvel. Foram esboçadas alternativas de produtos com base no painel semântico e nos requisitos de projeto. Ao final dessa fase, foi realizada a avaliação das alternativas geradas e selecionada uma de cada grupo, a partir dos critérios de viabilidade de produção, a lona como elemento diferencial e viabilidade comercial. 

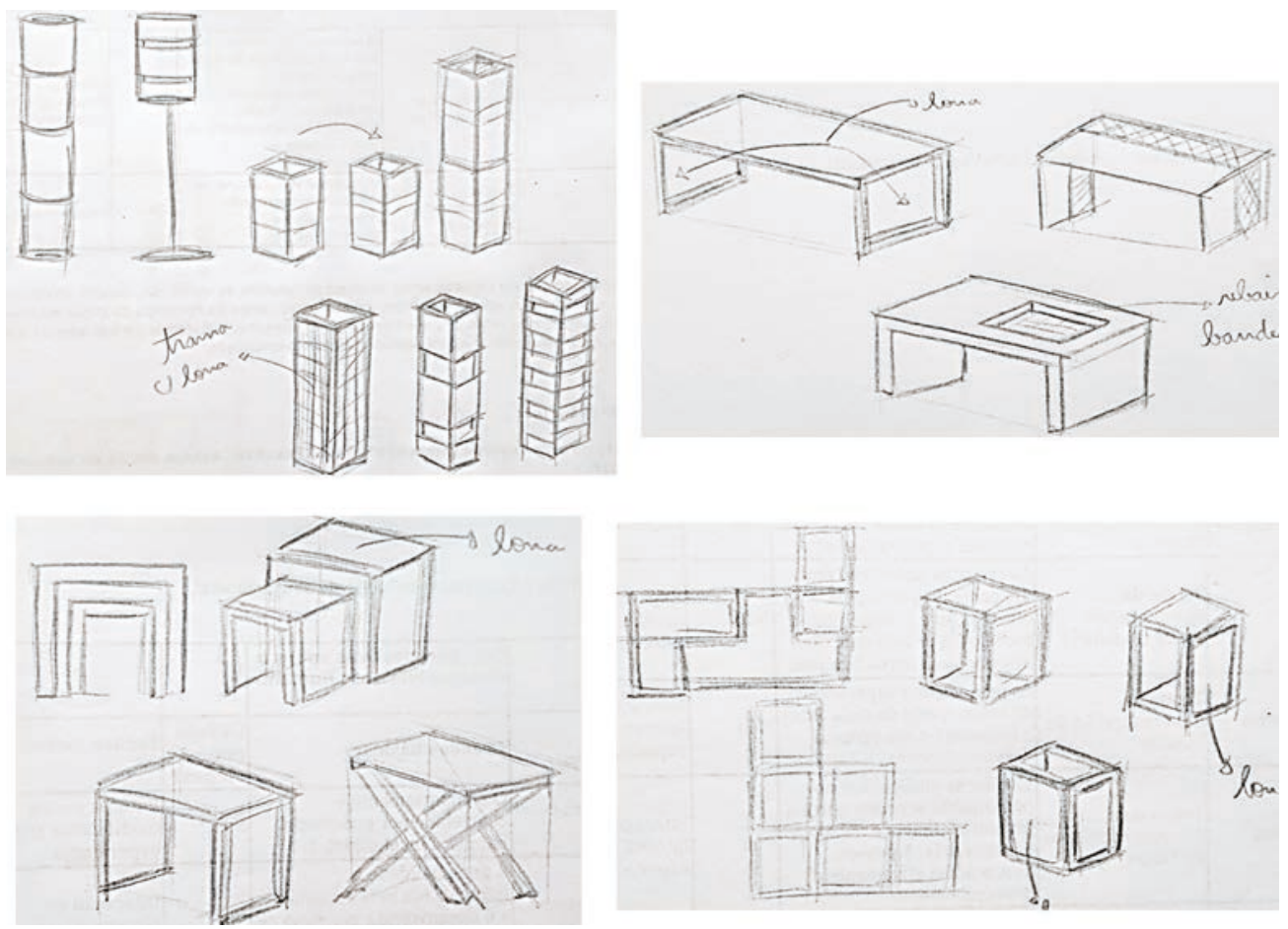

Figura 10 - Esboços da etapa de geração de alternativas.

Fonte: os autores.

Por fim, teve início a etapa de realização da solução do problema, a partir do detalhamento técnico das propostas e da produção dos protótipos. A fase de projeto resultou em quatro propostas de produtos diferentes: luminária de coluna (Figura 9a), mesa de centro com bandeja em baixo relevo (Figura 9b), bancos dobráveis (Figura 9c) e nichos empilháveis (Figura 9d). Todos os produtos utilizaram como matériaprima a madeira com acabamento natural e os banners de lona como elemento funcional e estético.

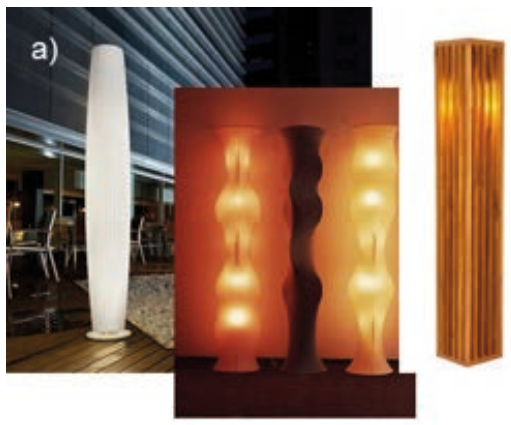

b)
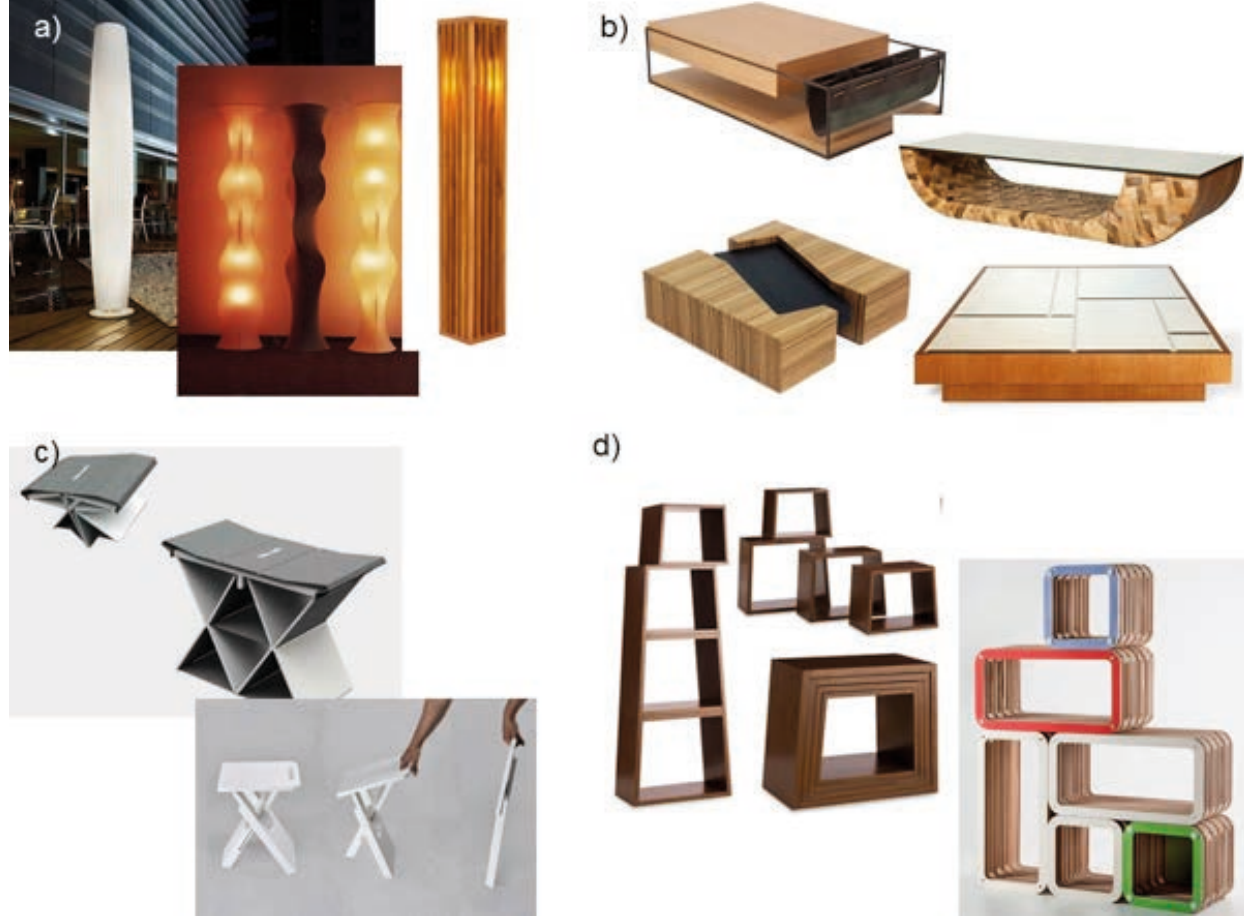

d)

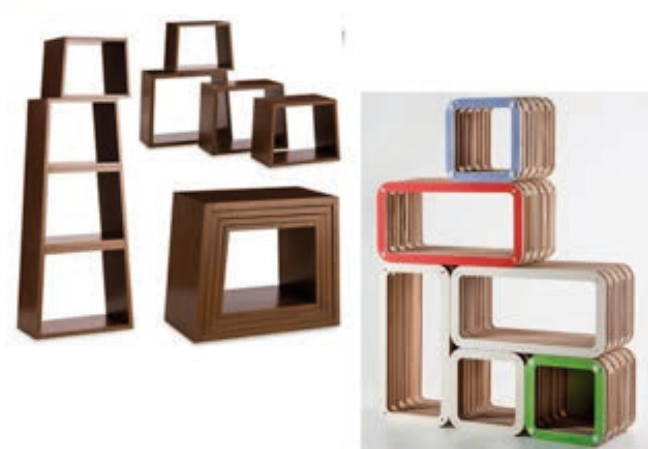

Figura 11 - Produtos produzidos a partir da aplicação de lonas de banners: a) luminárias de coluna; b) mesa de centro; c) bancos dobráveis; d) nichos empilháveis.

Fonte: os autores 
A luminária de coluna (Figura 9a) tem formato retangular, estrutura produzida a partir de molduras de madeira, com a base quadrada medindo $30 \mathrm{~cm} \times 30 \mathrm{~cm}$ e $140 \mathrm{~cm}$ de altura. A reutilização dos banners de lona se dá no revestimento da estrutura e é responsável pelo efeito de luz. Tiras de lona de diferentes alturas revestem a base, com uma distância entre essas tiras, por onde passa a luz. A diferença de cores e texturas entre a frente e o verso dos banners valoriza a estética do produto.

A mesa de centro retangular (Figura 9b) tem estrutura de madeira maciça, mede $90 \mathrm{~cm}$ de largura, $60 \mathrm{~cm}$ de profundidade e $40 \mathrm{~cm}$ de altura. 0 tampo da mesa possui um recorte retangular, abaixo do qual é fixada uma trama de tiras de lona vinílica. O rebaixo com o fundo de lona funciona como uma bandeja embutida no móvel.

Já o banco dobrável (Figura 9c) é um produto de fácil transporte e manuseio, ideal para atividades ao ar livre. Possui estrutura em madeira maciça e a lona é aplicada no assento. Suas dimensões são $45 \mathrm{~cm}$ de altura, $35 \mathrm{~cm}$ de largura e $38 \mathrm{~cm}$ de profundidade. A estrutura em " $X$ " do banco possibilita que ele seja dobrado, reduzindo as suas dimensões e facilitando o transporte.

Com a finalidade de reduzir o peso do produto e viabilizar a reutilização de materiais, optou-se por compor as laterais dos nichos empilháveis (Figura 9d) com banners de lona, tensionados e fixos na estrutura de madeira. Cada nicho é composto por duas molduras unidas por oito peças retangulares de madeira, fixadas verticalmente aos pares em cada uma das extremidades das molduras. As peças têm entre si a distância de $2 \mathrm{~mm}$, fresta por onde passam os retalhos de lona que formarão as laterais. O fundo, do mesmo material das laterais, é colado no rebaixo de umas das molduras do módulo. Os nichos são quadrados com dimensões de $30 \mathrm{~cm}$.

Os protótipos das luminárias de coluna, da mesa de centro, dos bancos dobráveis e dos nichos empilháveis foram produzidos nas dependências do laboratório de Móveis do IFFar, Campus Santa Rosa. Os produtos resultantes contemplam as premissas do Ecodesign de reutilização de materiais e processo produtivo simplificado, bem como demonstram a viabilidade da reutilização dos banners de lona na produção de móveis e acessórios.

\section{CONSIDERAÇÕES FINAIS}

A missão dos Institutos Federais é promover a educação profissional por meio do ensino, pesquisa e extensão. A pesquisa tem papel fundamental na consolidação da proposta de ensino dessas instituições. O trabalho com projetos de pesquisa com alunos do ensino médio faz com que, ao ingressarem no ensino superior, tenham conhecimento das etapas do processo e, consequentemente, maiores chances de êxito. O envolvimento dos alunos em todas as etapas da pesquisa e do desenvolvimento de produtos foi extremamente importante para os resultados alcançados.

Na óptica do Ecodesign, iniciativas de reutilização de materiais considerados resíduos na concepção de novos produtos é extremamente importante. Cabe ressaltar que a reciclagem de materiais poliméricos, que seria uma opção para a lona vinílica, é um processo oneroso e pouco difundido no país. A reutilização de materiais simplifica toda a produção, pois otimiza etapas. O processo inicial de extração e preparo da matéria-prima, que muitas vezes é o mais agressivo ao meio ambiente, não é necessário. Ainda, as etapas de acabamento são simplificadas ou desnecessárias quando se reutiliza um material.

Algumas características da lona vinílica como material eram previamente conhecidas, como a qualidade do acabamento superficial, a impermeabilidade e a durabilidade. Os testes de viabilidade demonstraram a viabilidade da união com a madeira e o MDF, materiais estruturais utilizados na produção de mobiliário. Ainda que os adesivos em geral não obtiveram resultados satisfatórios, a cola de contato pode ser utilizada, desde que em condições ambientais favoráveis, ou seja, com baixa umidade. Já a união mecânica com grampos metálicos mostrou-se mais resistente do que o esperado. Com relação ao acabamento, o insucesso da aplicação das tintas na superfície da lona reforça a concepção do Ecodesign de que o acabamento original do material é sempre a melhor opção. 
Já o teste de deformação realizado foi primário, dentro das possibilidades disponíveis nos laboratórios da instituição. Os resultados transcorreram dentro do esperado para materiais poliméricos, com locais de deformação plástica após a aplicação de carga localizada. Para trabalhos futuros seria interessante sujeitar o material à série de testes de resistência e deformação previstos nas normas, em um laboratório adequado. Ainda, seria relevante avaliar o comportamento do material após a aplicação nos produtos.

Por fim, cabe ressaltar que as propostas de produtos resultantes do projeto são apenas quatro possibilidades de aplicação da lona vinílica no design de móveis e acessórios. Os móveis resultantes demonstram que é possível desenvolver propostas a partir da reutilização de materiais com design contemporâneo, produção otimizada, passíveis de serem comercializadas a um preço acessível. Retomando Gomes (2011), é importante desmistificar a percepção generalizada de que um objeto reutilizado é degradado, de menor valor e pouco higiênico. Isso acontece em função da dificuldade de desassociar o sentimento negativo que existe em relação aos resíduos. O objetivo final desta pesquisa é demonstrar a viabilidade de propostas que auxiliem a mudança para uma situação em que as questões ambientais sejam inerentes dentro do processo de desenvolvimento de produtos (SHELDRICK; RAHIMIFARD, 2013).

\section{REFERÊNCIAS}

ASHBY, Michael; JOHNSON, Kara. Materiais e design: arte e ciência da seleção e materiais no design de produto. Rio de Janeiro: Elsevier, 2011.

CASSILHA, Antônio Carlos et al. Indústria moveleira e resíduos sólidos: considerações para o equilíbrio ambiental. Educação \& Tecnologia: CEFETs PR/MG/RJ, 2003.

D’AVILA, Fernanda; LENZI, Teresa. Re-utilizar para educar e minimizar problemas socioculturais. In: 13ạ Mostra da Produção Universitária. Rio Grande, 2014.

FUAD-LUKE, Alastair. The eco-design handbook: a complete sourcebook for the home and office. London: Thames \& Hudson, 2004.

GOMES, Daniel D.T. de C. O r em Design: a reutilização aplicada ao design. 2011. 104 p. Dissertação (Mestrado em Design Industrial). Faculdade de Engenharia, Universidade do Porto, Portugal, 2011.

HERMES, Letícia; MORGENSTERN, Elenir C. Ecobanner: Reaproveitamento sustentável de lonas vinílicas. Blucher Design Proceedings, Belo Horizonte, v. 9, n. 2, 2016.

JUNG, Aliar A.; SALDANHA, Mateus A.; GONÇALVES, Juliana A.; TOCCHETTO, Marta R.L.; DIC, Carmem. Projeto Relona: Reaproveitamento de lonas de banner. In: 4으의rum Internacional Ecoinovar, Santa Maria, 2015.

KAZAZIAN, Thierry (org.). Haverá a idade das coisas leves: design e desenvolvimento sustentável. 2 ed. São Paulo: Senac, 2005.

KINDLEIN JÚNIOR, Wilson et al. Princípios básicos de junção utilizados em sistemas e subsistemas de produtos industriais e sua importância no desenvolvimento sustentável. In: Associação Nacional de Pós-Graduação e Pesquisa em Ambiente e Sociedade, 1., 2002, Campinas. Anais. São Paulo, 2002. CD-ROOM.

LÖBACH, Bernd. Design Industrial: Bases para a configuração dos produtos industriais. São Paulo: Edgard Blücher, 2001.

MARTINUSSI, Júlia C.; ROSA, Rodrigo P.; GOYA, Cláudio R. Projeto Kid Vinil: um estudo de caso para a reutilização de resíduos de lona vinílica. In: 9o Congresso Brasileiro de Pesquisa e Desenvolvimento em Design. São Paulo, 2010. 
PADILHA, Ângelo Fernando. Materiais de engenharia: microestrutura e propriedades. Curitiba: Hemus, 2000.

PIGOSSO, Daniela C.A.; ZANETTE, Evelyn T.; GUELERE FILHO, Américo; OMETTO, Aldo R.; ROZENFELD, Henrique. Ecodesign methods focused on remanufacturing. Journal of Cleaner Production, n. 18, p. 21-31, 2010.

PLATCHECK, E. R.; SCHAEFFER, L.; KINDLEIN JR., W.; CÂNDIDO, L. H. A. Ecodesign: case of a minicompressor re-design. Journal of Cleaner Production, p. 1-10, 2007.

SHELDRICK, Leila; RAHIMIFARD, Shahin. Evolution in Ecodesign and Sustainable Design Methodologies. 20th CIRP International Conference on Life Cycle Engineering, Singapore, 2013. 